\title{
p53 R72P Alone and in Combination with MDM2 SNP T309G is Associated with Colon Carcinoma Incidence and Survival
}

\author{
Mannan $\mathbf{A}^{1}$, Ahmad $\mathrm{A}^{1}$ and Hahn-Strömberg $\mathbf{V}^{1,2^{*}}$ \\ ${ }^{1}$ Department of Clinical Research, Faculty of Medicine and Health, Orebro University, SE 70182, Orebro, Sweden \\ ${ }^{2}$ Department of Medical Cell Biology, Uppsala University, SE 75105, Uppsala, Sweden
}

*Corresponding author: Victoria Hahn-Strömberg, Department of Medical Cell Biology, Uppsala University, Uppsala, Sweden, Tel: +46184710000, E-mail: victoriastromberg@hotmail.com

Received date: April 11, 2016; Accepted date: May 18, 2016; Published date: May 20, 2016

Copyright: @ Mannan A, et al. This is an open-access article distributed under the terms of the Creative Commons Attribution License, which permits unrestricted use, distribution, and reproduction in any medium, provided the original author and source are credited.

\begin{abstract}
Introduction: Protein p53 is encoded by tumor suppressor TP53, which regulates key cellular functions such as transcription, cell cycle arrest, DNA repair and apoptosis. Murine double minute 2 homolog (MDM2), a p53 transcribed protein, negatively regulates p53. A single nucleotide polymorphism (SNP) at codon 72 of TP53 (R72P, rs1042522) alters an amino acid, while an SNP T309G (rs2279744) polymorphism (SNPT309G) in the promoter region of MDM2 has been reported to modulate its transcription. p53 R72P and MDM2 SNPT309G have been reported to associate alone and or in combination with various carcinomas. In this study, we aimed to determine if p53 R72P and MDM2 SNPT309G polymorphism alone or in combination are associated with colon carcinoma incidence, tumor progression and/or patient survival in Swedish population.
\end{abstract}

Materials and methods: We determined polymorphisms in 151 colon carcinoma patients and 188 healthy controls by PCR-Pyrosequencing. For statistical analysis, we applied logistic regression analysis, Chi square and multivariate Cox regression to determine incidence, progression of colon carcinoma and overall patient survival respectively. Statistical analyses were two sided.

Results: We found that individual carriers of Arg/Pro and Pro/Pro+Pro/Arg (Pro/--) are at $1.72(95 \% \mathrm{Cl}$; $1.09-2.72)$, and $1.659(95 \% \mathrm{Cl} ; 1.07-2.58)$ fold higher risk of developing colon carcinoma compared to the carriers of Arg/Arg individuals. We did not find association of MDM2 SNPT309G with incidence of colon carcinoma. No association was found between p53 and MDM2 polymorphisms and clinicopathological parameters, except for TT variant that was correlated with low-differentiated tumors. We also found that people with Arg/Pro and Pro/--- had significantly lower overall survival compared with the people having $\mathrm{Arg} / \mathrm{Arg}$ variants (Arg/Pro, OR; $1.75,95 \% \mathrm{Cl}$; 1.09-2.75, Pro/---, OR; 1.7, 95\% Cl; 1.065-2.68), but MDM2 polymorphism was not associated with patient survival. In combined analysis, with reference to Arg/Arg+TG/GG, Pro/---+TG/GG was marginally correlated with colon carcinoma incidence (OR; $1.75,95 \% \mathrm{Cl} ; 0.99-3.11)$, while Pro/----TT was significantly correlated with poor patient survival (OR; 2.03, 95\% Cl; 1.029-4.02).

Conclusion: p53 R72P polymorphism is associated with the incidence of colon carcinoma and patient survival. p53 and MDM2 polymorphism appear to interact with each other and modify the association with colon carcinoma incidence and patients' survival.

Keywords: p53 R72P; MDM2 SNPT309G; Colon carcinoma; Patient survival

\section{Introduction}

Colorectal cancer (CRC) is the third most common type of cancer in the world today. Globally, an estimated numbers of new cases of CRC were 1.36 million and an estimated death of tolls about 700000 , in 2012 alone. In Europe, estimated numbers of new cases of CRC were 447,136 and deaths 214,866 in the same year [1].

Etiologically, CRC is a multifactorial disease. Broadly, CRC associated factors are divided into three major groups i.e. genetic, epigenetic and environmental factors. Within the genetic factor, TP53 is one of the most studied gene for its role in cancer. TP53 encodes a 53 $\mathrm{KDa}$ nuclear protein, $\mathrm{p} 53$, which functions as a transcription factor to regulate the expression of multiple proteins. p53 and its regulated proteins play a pivotal role in the regulation of cell growth, cell cycle arrest, DNA repair and apoptosis [2-4]. Therefore, any mutation in TP53 may have an effect on p53 functions. Mutations in the p53 have been reported frequently in various human cancers [5-7]. Furthermore, different polymorphic variants of TP53 can also impact on p53 functions $[8,9]$.

Single nucleotide polymorphism (SNP) at codon 72 exon 4 of TP53 (rs1042522) has intensively been studied for its association with the risk and progression of CRC [10-15]. This polymorphism alters a single amino acid; found either in homozygous arginine (Arg/Arg; $\mathrm{G} / \mathrm{G}$ ), or homozygous proline (Pro/Pro; $\mathrm{C} / \mathrm{C}$ ) and/ or heterozygous proline/arginine (Arg/Pro; G/C). Amino acid fluctuate in a proline rich part of p53 that is indispensable in p53 facilitated apoptosis and can also affect other functions; the pro isoform of p53 is more active in causing transcription and cell cycle arrest, while the Arg variant is more efficient to induce apoptosis [16]. 
Murine double minute 2 protein (MDM2), a p53 transcribed protein [17], binds with $\mathrm{p} 53$, and prevents $\mathrm{p} 53$ mediated transcription of target genes [18]. MDM2 is a E3 ligase, thus it also enhances the degradation of p53 through E3 ubiquitination [19]. Because it negatively regulates p53, MDM2 is an important tumor marker and reported to over express in many human cancers [20,21]. Previously, Bond et al. reported that a single nucleotide polymorphism (SNP T309G, rs2279744) in the promoter region of MDM2 increases its expression levels due to higher binding affinities of the stimulatory protein 1 (SP1) transcription factor to GG genotype. Some epidemiological studies have also reported that, interaction between polymorphisms in p53 codon 72 (R72P) and in MDM2 SNPT309G are associated with increased risk of CRC [14,22-25].

The risk of the cancer due to polymorphic variations differs in different population groups $[12,26]$. Although the effect of p53R72P polymorphism as risk factor of colon carcinoma is studied in Swedish population [10], however none of the studies have been reported to determine the combined effect of p53 R72P and MDM2 SNP T309G polymorphisms in developing colon carcinomas. Furthermore, to our knowledge, no study has determined the effect of p53 and MDM2 polymorphisms alone and or in combination as risk, progression and survival factors in colon carcinoma. In this study we aimed to assess the separate and combined effects of p53R72P and MDM2 SNPT309G polymorphism on colon carcinoma development, progression and survival of the patients.

\section{Materials and Methods}

In this study, 151 formalin fixed paraffin embedded (FFPE) noncancerous colon tissues samples were selected from the patients diagnosed with colorectal carcinoma during 2002-2006. Rectal carcinomas were excluded from the study, as most of the patients diagnosed with rectal cancer acquire local radiation therapy before surgery. Blood samples from 188 blood and plasma donors were used as a control. Samples were blinded and numbered 1-151 for noncancerous patient colon tissue and 1-188 blood samples. Samples were collected randomly and consisted of both men and women. 70 and 81 patient colon tissues and 121 and 67 blood donor samples were from men and women respectively. Samples were collected from the Department of Clinical Laboratory Medicine, Section for Pathology, Örebro University Hospital, Örebro, Sweden. Ethical approval for the study was received from EPN Uppsala, Sweden.

\section{DNA extraction}

For genomic DNA extraction from blood and FFPE tissue, $5 \mathrm{ml}$ of blood, and $2 \mathrm{~mm}$ punches from the normal colon tissue of colon carcinoma patients were used. DNA was extracted by using Viogene Blood and tissue genomic DNA extraction Miniprep kit (New Jersey, USA), and from FFPE tissue by NucleoSpin ${ }^{\circ}$ FFPE DNA (MachereyNagel, Duren Germany) in accordance with manufacturer's instructions. Quality and concentrations of extracted genomic DNA were analyzed by using NanoDrop ND-1000 spectrophometer (Thermo Scientific, Wilmington USA), and extracted DNA samples were stored at $-20^{\circ} \mathrm{C}$.

\section{Genotyping}

For genotyping, polymerase chain reaction (PCR)-pyrosequencing method was used. Primers for PCR and pyrosequencing were designed by using PyroMark Assay Design 2.0 software (Qiagen sample and
Assay technology, Hilden Germany). Information regarding PCR primers annealing temperatures, sequences of reverse and forward PCR primers, sequencing primers and sequence to analyze are provided in the table (Table 1).

\begin{tabular}{|c|c|c|}
\hline Gene & $5^{\prime}-3^{\prime}$ & $\begin{array}{l}\text { Annealing } \\
\text { Temperature }\left({ }^{\circ} \mathrm{C}\right)\end{array}$ \\
\hline \multicolumn{3}{|l|}{ p53 } \\
\hline Forward Primer & 1CTGAAGACCCAGGTCCAGATG & 61 \\
\hline Reverse Primer & CCGGTGTAGGAGCTGCTG & NA \\
\hline Sequencing primer & GGTGCAGGGGCCACG & NA \\
\hline $\begin{array}{l}\text { Sequence to } \\
\text { analyse }\end{array}$ & SGGGGAGCAGCCTCTGGCAT & \\
\hline \multicolumn{3}{|l|}{ MDM2 } \\
\hline Forward Primer & GGGGTGGTTCGGAGGTCT & 61 \\
\hline Reverse Primer & 1GTGACCCGACAGGCACCT & \\
\hline Sequencing primer & GGGCTGCGGGGCCGCT & NA \\
\hline $\begin{array}{l}\text { Sequence to } \\
\text { analyse }\end{array}$ & KCGGCGCGGG AGGTCCGGA & NA \\
\hline
\end{tabular}

Table 1: PCR, Pyro sequencing Primer Sequences and annealing temperatures.

PCR master mix was prepared in a total volume of $50 \mu \mathrm{l}$ and it contained; genomic DNA $(50-100 \mathrm{ng} / \mu \mathrm{l})$, each of the reverse and forward primer $(0.25 \mu \mathrm{M})$, PCR buffer (1X), $\mathrm{MgCl}_{2}(1.5 \mathrm{mM})$, deoxyribonucleotides triphosphate $(\mathrm{dNTP})(200 \mu \mathrm{M})$ and KAPA2G Fast HotStart polymerase (1U). All PCR master mix reagents were purchased from KAPA biosystem (KAPA Biosystem, Boston Massachusetts, USA). Amplifications of DNA were performed in a thermal cycler 2700 GeneAmp $^{\circledR}$ (Applied Biosystems) with an initial denaturation at $96^{\circ} \mathrm{C}$ for 10 minutes, and then followed by 40 PCR cycle for p53 and 49 for MDM2; denaturation at $94^{\circ} \mathrm{C}$ for 45 seconds and annealing at $61^{\circ} \mathrm{C}$ for 30 seconds. PCR was ended after a final extension at $72^{\circ} \mathrm{C}$ for 7 minutes. PCR products were run in a $2 \%$ agarose gel for one hour and visualized under UV light in a UV transluminator (Bio-Rad Laboratories, CA, USA).

PyroMark Q 96 ID pyrosequencer (Qiagen.Biotage AB, Uppsala, Sweden) was used to determine single nucleotide polymorphisms according to the instructions provided by the manufacturer. In a summary, $25 \mu \mathrm{l}$ of amplified PCR products were mixed with $3 \mu \mathrm{l}$ solution of streptavidin sepharose ${ }^{\mathrm{Tu}}$ high performance (GE Healthcare Bio-Science AB, Uppsala, Sweden), $12 \mu \mathrm{l}$ of Milli Q water and $40 \mu \mathrm{l}$ binding buffer $(10 \mathrm{mmol} / \mathrm{L}$ Tris-HCL, $2 \mathrm{~mol} / \mathrm{Lnacl}, 1 \mathrm{mmol} / \mathrm{L}$ EDTA, $1.0 \%$ Tween 20 , milliq water $\mathrm{pH}$ 7.6). PCR products were immobilized by vacuum preparation tool then sequentially washed with $70 \%$ ethanol, denaturing buffer and washing buffer and finally released in a sequencing primer mix in 96 well sequencing plate. The 96 well sequencing plate were kept at $80^{\circ} \mathrm{C}$ for two minutes and then cooled at room temperature for 10 minutes before pyrosequencing. SNPs were analyzed by using PyroMark ID 1.0 software (Biotage, Sweden). 
Page 3 of 8

\section{Statistical analysis}

For statistical analysis, SPSS version 20 software (SPSS, Inc, Chicago, IL, USA) was used. Analyses of the quantitative variables were performed by calculating their means and standard deviation, while for the qualitative variables, by the percentages and frequencies. To determine the statistical correlation, the Chi-square or Fisher exact test were applied appropriately among different grouped variables. To estimate relative risk of cancer with specific genotype, binomial logistic regression analysis was applied to determine odds ratio (OR) and confidence interval (CI) of $95 \%$ after adjusting for the gender. The Kaplan Meier survival analysis with long rank significance test was used to construct survival curves and to estimate the median survival. Multivariate cox regression survival analyses were performed to estimate significance, OR and 95\% CI for the carriers of p53 and MDM2 polymorphisms after adjusting for the age at diagnosis, gender, tumor stages and differentiation. A P-value of less than 0.05 was considered as statistically significant.

\section{Results}

\section{Participant data}

Collection of tissue and blood samples were made randomly from patients and healthy individuals, resulting in statistically significant differences in gender between two groups $(0.05>\mathrm{P})$ : $121(64 \%)$ men and $67(36 \%)$ women in the control group and $70(46 \%)$ men and 81 (54\%) women in the patient cohort.

The clinicopathological parameters of the patients are summarized in Table 2. Colon cancer patients were diagnosed at different ages, ranging from 47 to 95 years with the mean age of 75 and SD of 9.7 years. Among the colon cancer patients, 85 (56\%) cases had cancer in right colon, $63(42 \%)$ in right side colon, and the remaining $3(2 \%)$ cases with missing information on tumor location. According to the WHO system of tumor classification, out of 146 (five samples were mucinous), 23 (16\%) tumors were low differentiated, 95 (65\%) medium and $28(19 \%)$ highly differentiated. Tumor node metastasis classification of tumor showed that $82 \%$ (125) of the cases had tumour gut wall penetration score of $\mathrm{T} 3$ and $\mathrm{T} 4,40 \%$ (60) were positive for lymph node metastasis and 2\% (3) for distant metastasis.

\begin{tabular}{|c|c|c|}
\hline Clinicopathological characters & Total & $\mathbf{N}(\%)$ \\
\hline \multicolumn{3}{|l|}{ Gender } \\
\hline Male & 70 & 46.4 \\
\hline Female & 81 & 53.6 \\
\hline \multicolumn{3}{|l|}{ Age } \\
\hline $70 \leq$ & 46 & 30.5 \\
\hline$>70$ & 105 & 69.5 \\
\hline \multicolumn{3}{|l|}{ Localization } \\
\hline Right Colon & 85 & 57 \\
\hline Left Colon & 63 & 43 \\
\hline \multicolumn{3}{|l|}{ Differentiation } \\
\hline Low & 23 & 15.8 \\
\hline
\end{tabular}

\begin{tabular}{|c|c|c|}
\hline Medium & 95 & 65.1 \\
\hline High & 28 & 19.2 \\
\hline \multicolumn{3}{|c|}{ Tumor penetration $(\mathrm{T})$} \\
\hline $\mathrm{T} 1+\mathrm{T} 2$ & 26 & 17.2 \\
\hline $\mathrm{T} 3+\mathrm{T} 4$ & 125 & 82.8 \\
\hline \multicolumn{3}{|c|}{ lymph node (N) } \\
\hline Absent & 91 & 60.3 \\
\hline Present & 60 & 39.7 \\
\hline \multicolumn{3}{|l|}{ M } \\
\hline 1 & 3 & 2 \\
\hline$x$ & 148 & 98 \\
\hline \multicolumn{3}{|l|}{ Dukes } \\
\hline$A+B$ & 91 & 60.3 \\
\hline$C+D$ & 60 & 39.7 \\
\hline
\end{tabular}

Table 2: Different clinical and pathological parameters of patient cohort.

\section{Genetic data}

Representative Pyroprograms of different polymorphic forms of p53 R72P and SNP T309G MDM2 are shown (Figures 1 and 2).

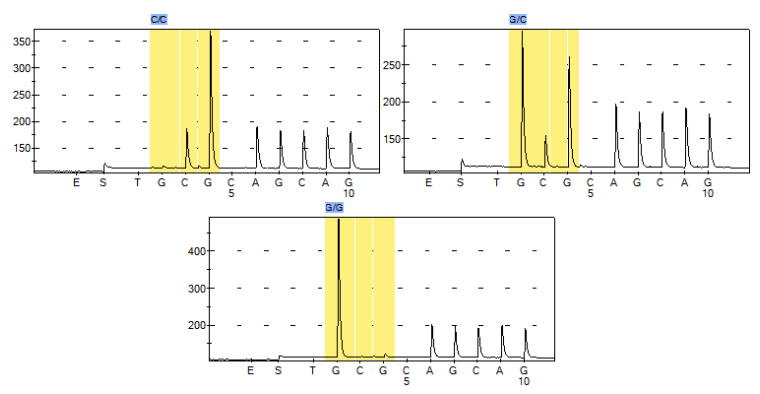

Figure 1: Pyrograms of p53 Arg72Pro genotype. Since, sequencing primer was reverse, therefore complementary to G/ CGGGGAGCAGCC (complementary) sequence is GGCTGCTCCCCG/C (coding sequence). Pyrogram A, is pyrogram of homozygous GG, B heterozygous GC and C homozygous mutant p53 R72P genotype.

In the healthy group, GG was the highest (56.9\%) form of p53 variant, followed by GC (37.8\%) and CC (6.4\%). While, in the patient group, GC (49\%) was the highest p53 variant followed by GG (43\%) and CC (8\%) (Table 4). The frequencies of MDM2 polymorphisms were comparable between healthy and patient individuals with TG was the highest variant followed by TT and then GG (Table 4). Frequency distributions of the TP53 R72P and MDM2 SNPT309G followed the Hardy-Weinberg principle (Figure 2). 
Page 4 of 8

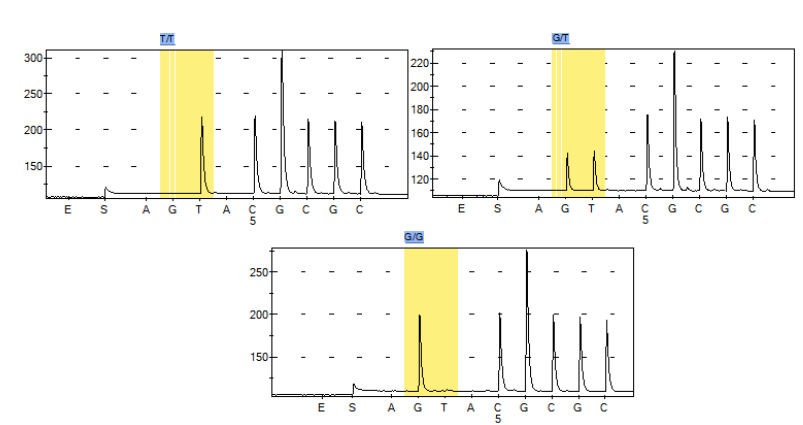

Figure 2: Pyrograms for MDM2 T309T genotype; $A$ is a representative pyrogram of homozygous wild type TT, B heterozygous mutant TG and C homozygous mutant GG genotype.

\section{Association of p53 R72P and MDM2 SNP T309G with risk of colon carcinoma}

Table 3 represents association between p53 R72P and MDM2 SNP 309 with colon carcinoma. After taking Arg/Arg as reference, Arg/Pro and Arg/Pro +Pro/Pro (Pro/--) showed a significant increased risk of colon carcinoma with an OR and a P value of 1.72 and 0.02 (95\% CI: 1.088-2.719), and 1.659 and 0.024 (95\% CI: 1.068-2.578), respectively. There was no significant association between Pro/Pro versus Arg/arg and colon cancer, most probably because of low frequencies of Arg/Arg in both patients and healthy individuals. For the MDM2 T309G polymorphism, GG, TG and TG+GG with reference to TT showed no differences between patient and control groups with an OR of 0.93 (95\% CI:0.586-1.500), 0.709 (95\% CI:0.348-1.443) and 0.88 (95\% CI:0.565-1.374), respectively.

\begin{tabular}{|c|c|c|c|c|c|c|}
\hline \multirow{2}{*}{$\begin{array}{l}\text { Clinicopathologi } \\
\text { cal parameters }\end{array}$} & \multicolumn{2}{|l|}{ p53 R72P } & \multirow{2}{*}{$\begin{array}{l}\begin{array}{l}\mathrm{P}- \\
\text { value }\end{array} \\
T T \\
\mathrm{~N}(\%)\end{array}$} & \multicolumn{2}{|c|}{ MDM2 SNP T309G } & \multirow{2}{*}{$\begin{array}{l}P \text { - } \\
\text { value }\end{array}$} \\
\hline & $\begin{array}{l}\text { Arg/Arg } \\
\mathrm{N}(\%)\end{array}$ & $\begin{array}{l}\text { Pro/-- } \\
\text { N(\%) }\end{array}$ & & $\begin{array}{l}\text { TG+GG } \\
\mathrm{N}(\%)\end{array}$ & & \\
\hline Gender & & & 0.77 & & & 0.35 \\
\hline Male & $31(48.4)$ & $39(45.3)$ & & $32(50.7)$ & $38(43.2)$ & \\
\hline Female & $34(52.6)$ & $47(54.7)$ & & $31(49.3)$ & $50(56.8)$ & \\
\hline Age & & & 0.32 & & & 0.133 \\
\hline $70<$ & $17(26.2)$ & $29(73.8)$ & & $15(24)$ & $31(35)$ & \\
\hline$\geq 70$ & $48(33.7)$ & $57(66.3)$ & & $48(76)$ & $57(65)$ & \\
\hline *Localisation & & & 0.2 & & & 0.089 \\
\hline Right & $33(51.6)$ & $52(62)$ & & $30(49)$ & $55(63)$ & \\
\hline Left & $31(48.4)$ & $32(38)$ & & $31(51)$ & $32(37)$ & \\
\hline${ }^{* *}$ Differentiation & & & 0.85 & & & 0.038 \\
\hline Low & $10(15.6)$ & $13(16)$ & & $15(24.6)$ & $8(9.4)$ & \\
\hline Medium & $43(67.2)$ & $52(63)$ & & $37(60.7)$ & $58(68.2)$ & \\
\hline High & $11(17.2)$ & $17(21)$ & & $9(14.8)$ & $19(22.4)$ & \\
\hline
\end{tabular}

\begin{tabular}{|l|l|l|l|l|l|l|}
\hline $\begin{array}{l}\text { Tumor } \\
\text { Penetration }\end{array}$ & & & 0.43 & & & 0.97 \\
\hline T1+T2 & $13(20)$ & $13(15)$ & & $11(17.5)$ & $15(17)$ & \\
\hline T3+T4 & $52(80)$ & $73(85)$ & & $52(82.5)$ & $73(83)$ & \\
\hline lymph node (N) & & & 0.105 & & & 0.094 \\
\hline Absent & $44(68)$ & $47(55)$ & & $33(52.4)$ & $58(66)$ & \\
\hline Present & $21(32)$ & $39(45)$ & & $30(47.6)$ & $30(34)$ & \\
\hline M & & & 0.26 & & & 0.071 \\
\hline 1 & 0 & $3(3.5)$ & & $3(4)$ & 0 & \\
\hline X & $44(100)$ & $83(96.5)$ & & $60(95)$ & $88(100)$ & \\
\hline Dukes staging & & & 0.105 & & & 0.094 \\
\hline A+B & $21(32)$ & $39(45)$ & & $30(47.6)$ & $30(34)$ & \\
\hline C+D & & & & & & \\
\hline
\end{tabular}

Table 3: Association between p53 R72P and MDM2 SNP T309G and clinicopathological parameters.

\section{Association of p53 R72P and MDM2 SNP T309G with clinicopathological parameters}

We also associated various polymorphic forms of p53 R72P and MDM2 SNPT309G with different clinicopathological parameters such as age, gender, localization, TNM and Duke Stages of the patients. Different polymorphic forms of p53 R72P and MDM2 SNP 309 showed non-significant relationship with all clinical parameters (data not shown). When we dichotomized p53 and MDM2 variants; Arg/Arg and Pro/---, and TT and TG/GG respectively, none of the parameters was significantly associated with different forms of p53 with the exception of TT variant of MDM2, which was significantly correlated with lower differentiated tumors $(\mathrm{P}=0.035)$ (Table 4$)$. The TT genotype also showed a trend for left sided colon carcinoma $(\mathrm{P}=0.089)$ and advanced tumors stages such as lymph node metastasis $(\mathrm{P}=0.094)$, distant metastasis $(\mathrm{P}=0.07)$ and $\mathrm{C}+\mathrm{D}$ Duke Stages $(\mathrm{P}=0.094)$ (Table 4).

\begin{tabular}{|c|c|c|c|c|c|c|}
\hline \multicolumn{2}{|c|}{ Genotypes } & $\begin{array}{l}\text { Control } \\
\text { N (\%) }\end{array}$ & $\begin{array}{l}\text { Cases } \\
\mathrm{N}(\%)\end{array}$ & $\begin{array}{l}P \\
\text { value }\end{array}$ & aOR & $95 \% \mathrm{Cl}$ \\
\hline \multicolumn{2}{|c|}{ p53 } & 188 & 151 & & & \\
\hline \multicolumn{2}{|c|}{ Arg/Arg } & $105(57)$ & $65(43)$ & 0.00 & 1.00 & Referent \\
\hline \multicolumn{2}{|c|}{ Arg/Pro } & $71(37.8)$ & 75 (49) & 0.02 & 1.72 & $1.09-2.72$ \\
\hline \multicolumn{2}{|c|}{ Pro/Pro } & $12(6.4)$ & $11(8)$ & 0.542 & 1.32 & $0.54-3.22$ \\
\hline \multicolumn{2}{|c|}{ Pro/--- } & $83(44.1)$ & $86(57)$ & 0.024 & 1.659 & $1.07-2.58$ \\
\hline \multicolumn{7}{|c|}{ MDM2 } \\
\hline \multicolumn{2}{|l|}{ TT } & 74 (39.4) & $63(41.7)$ & 0.636 & 1.00 & (Rerferent) \\
\hline \multicolumn{2}{|l|}{ TG } & $85(45.2)$ & $72(47.7)$ & 0.78 & 0.93 & $0.586-1.500$ \\
\hline \multicolumn{2}{|l|}{ GG } & $29(15.4)$ & $16(10.6)$ & 0.34 & 0.709 & $0.348-1.443$ \\
\hline \multicolumn{2}{|c|}{$T G+G G$} & $114(60.6)$ & $88(58.3)$ & 0.58 & 0.88 & $0.565-1.374$ \\
\hline p53 & MDM2 & & & & & \\
\hline
\end{tabular}


Citation: Mannan A, Ahmad A, Hahn-Strömberg V (2016) p53 R72P Alone and in Combination with MDM2 SNP T309G is Associated with Colon

Page 5 of 8

\begin{tabular}{|l|l|l|l|l|l|l|}
\hline Arg/Arg & TT & $36(19.4)$ & $26(17.2)$ & 0.00 & 1.00 & (Rerferent) \\
\hline Pro/--- & TT & $36(19.4)$ & $37(24.5)$ & 0.337 & 1.405 & $0.702-2.81$ \\
\hline Arg/Arg & TG+GG & $67(36)$ & $39(25.8)$ & 0.523 & 0.809 & $0.422-1.551$ \\
\hline Pro/--- & TG+GG & $47(25.3)$ & $49(32.5)$ & 0.295 & 1.42 & $0.737-2.73$ \\
\hline Arg/Arg & TG+GG & $47(25.3)$ & $49(32.5)$ & 0.00 & 1.00 & (Rerferent) \\
\hline Pro/--- & TG+GG & $67(36)$ & $39(25.8)$ & 0.054 & 1.75 & $0.99-3.11$ \\
\hline Pro/--- & TT & $36(19.4)$ & $37(24.5)$ & 0.079 & 1.74 & $0.939-3.216$ \\
\hline
\end{tabular}

Table 4: Binomial Regression Analysis for Incidence of Colon Carcinoma.

\section{Association of p53 R72P and MDM2 SNP T309G with patient survival}

We further analyzed that if different polymorphic variants of p53 and MDM2 genes associate with the overall patient survival (Table 5). The follow up time for our patient cohort was 60 months, during which 87 patients (58\%) died and the rest were censored. The survival analyses were adjusted for potential confounders such as age, gender, TNM, differentiation and Dukes stages (Figure 3).
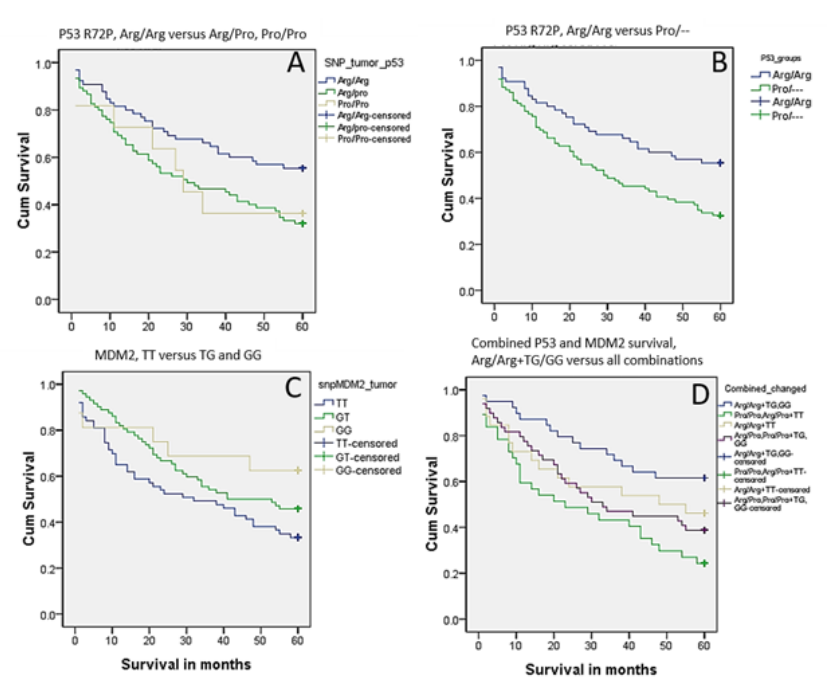

Figure 3: Graphs displaying Cum survival and Survival in months.

A - Represents survival for patients carriers for different variants of p53. Significant results are apparent between Arg/Arg and Arg/Pro carries. Though differences are also present between Arg/Arg and Pro/Pro but results are non-significant due to lower frequency of Pro/Pro variant. B - Survival anaylsis between the patients' carrier of Arg/Arg and Pro/--- (Arg/Pro+Pro/Pro) group variables. C - Survival curve does not show big differences in the survival for patients with various form of MDM2 SNP309. D - Combined analysis for survival of patients with different p53 and MDM2 SNP309 polymorphisms. While taking Arg/Arg,TT as reference, non-significant results were observed with different groups. However, carriers of Pro/---,TT were significantly associated with poor survival compared to Arg/Arg, TG/GG carriers.
According to p53 polymorphic varients, compared with Arg/Arg that was taken as a reference, Arg/Pro and Arg/Pro+Pro/Pro (Pro/--) showed significantly lower overall survival with an $\mathrm{OR}$ and $\mathrm{P}$ value of 1.75 and 0.02 ( $95 \% \mathrm{CI}: 1.09-2.79$ ) and 1.7 and 0.026 (95\% CI: $1.065-2.68)$ respectively.

Although patients with Pro/Pro polymorphic form of p53 showed less favorable outcome but the results were non-significance most probably because of small sample numbers of patients with homozygous Pro. W (Table 5). For MDM2 SNP 309 polymorphism, insignificant associations were observed with overall patient survival, when TG, GG and TG+GG variants were compared with TT (Figure 3).

\begin{tabular}{|c|c|c|c|c|c|}
\hline Gene & Genotypes & $\begin{array}{l}\text { Median } \\
\text { Survival } \\
\text { (Months) }\end{array}$ & $P$ value & OR & $95 \% \mathrm{Cl}$ \\
\hline \multirow{4}{*}{ p53 } & Arg/Arg & --- & 0 & 1 & Referent \\
\hline & Arg/Pro & 30 & 0.02 & 1.75 & $\begin{array}{l}1.09-2.7 \\
9\end{array}$ \\
\hline & Pro/Pro & 29 & 0.546 & 1.31 & $\begin{array}{l}0.55-3.1 \\
23\end{array}$ \\
\hline & Pro/--- & 29.5 & 0.026 & 1.7 & $\begin{array}{l}1.065-2 . \\
68\end{array}$ \\
\hline \multirow{4}{*}{ MDM2 } & TT & 32 & 0 & 1 & Referent \\
\hline & TG & 41 & 0.818 & 0.947 & $\begin{array}{l}0.6-1.50 \\
2\end{array}$ \\
\hline & GG & --- & 0.336 & 0.648 & $\begin{array}{l}0.258-1 \\
57\end{array}$ \\
\hline & GG/TG & 54 & 0.63 & 1.12 & $\begin{array}{l}0.714-1 \\
747\end{array}$ \\
\hline \multicolumn{6}{|c|}{ Combined Analysis } \\
\hline p53 & MDM2 & & & & \\
\hline Arg/Arg & TT & 48 & 0 & 1 & Referent \\
\hline *Pro/--- & TT & 23 & 0.1 & 1.77 & $\begin{array}{l}0.895-3 . \\
51\end{array}$ \\
\hline Arg/Arg & TG/GG & -- & 0.835 & 0.922 & $\begin{array}{l}0.431-1 \\
97\end{array}$ \\
\hline Pro/--- & TG/GG & 33 & 0.218 & 1.51 & $\begin{array}{l}0.782-2 . \\
933\end{array}$ \\
\hline${ }^{*} \operatorname{Arg} / \operatorname{Arg}$ & TG/GG & --- & 0 & 1 & Referent \\
\hline Pro/--- & TG/GG & 33 & 0.116 & 1.68 & $\begin{array}{l}0.88-3.2 \\
04\end{array}$ \\
\hline Pro/--- & $\mathrm{TT}$ & 23 & 0.041 & 2.03 & $\begin{array}{l}1.029-4 . \\
02\end{array}$ \\
\hline
\end{tabular}

Table 5: Multivariate Cox Regression Analysis for Patient Survival. 


\section{Combined association of p53 R72P and MDM2 SNP 309 with colon carcinoma: risk, progression and patient survival}

As p53 and MDM2 interact with each other, we also reported combined analyses for different polymorphisms in p53 and MDM2. By taking GG+TT as reference, various combinations showed nonsignificant differences between patients and healthy individuals (Table 4). We did further analysis to compare if Pro/---+TG/GG and Pro/--+TT versus Arg/Arg+TG/GG, by assuming that p53 status alters its binding with the MDM2 pomoter and or protein, which ultimately might change the risk of colon carcinoma. We found that Pro/--. +TG/GG combination showed marginally significant association with colon carcinoma with OR and P value of 1.75 and 0.054 (95\% CI: 0.99-3.11). Though, Pro/---+TT showed a trend, but the results were non-significant (Table 4). Combined genotypes of p53 and MDM2 were also associated with the various clinical and pathological parameters, but none of the combinations were significantly correlated with clinical and pathological parameters (Data not shown).

When different combinations were compared against Arg/Arg and TT genotypes of p53 and MDM2 respectively, no effect was observed on the overall survival the patients (Figure 3 and Table 5). However, when we compared Arg/Arg+TG/GG that was taken as reference with the Pro/---+TG/GG and Pro/---+TT: the Pro/---+TT combination was significantly associated with poor overall patient survival $(\mathrm{P}=0.041$, OR; 2.03, $95 \%$ CI; 1.029-4.017).

\section{Discussion}

Different populations differ in their susceptibility of CRC. The best explanation of this came from the knowledge of different polymorphic variants of various genes; particularly those involved in cell cycle control and DNA repair mechanism, and their frequency varies among different population. $\mathrm{p} 53$ is one of the most studied proteins that plays fundamental role in regulating basic cellular function and because of this, it is an important target protein to study different polymorphic variants of $\mathrm{p} 53$ for their association with various diseases including colon carcinomas [10,12-14,27]. A SNP in MDM2 (SNPT309G), a negative regulator of $\mathrm{p} 53$, alone or in combination with $\mathrm{p} 53$ has been reported to associate with different carcinomas and progression of disease [14,18,22,23,25,27-30]. Over the last decade, studies have reported the role of $\mathrm{p} 53 \mathrm{R} 72 \mathrm{P}$ and MDM2 T309G polymorphisms as risk factor for colorectal carcinoma [14,15,19,23-25]. To our knowledge there is no study which have shown the impact of p53 R72P and MDM2 T309G alone or in combination on the CRC patient survival. Also, there are only one study which reported the association of 553 R72P polymorphism in CRC [10]in the Swedish population.

In this study, we examined the association of p53 R72P and MDM2 T309G polymorphism separately and combined with colon carcinoma by randomly selecting 151 cases and 188 controls individual from central Sweden. The frequencies of p53 R72P and MDM2 SNP T309T polymorphism within normal population were consistent with earlier studies in Sweden [10,31].

We found that, p53 polymorphism was significantly associated with the increased risk of colon cancer (Table 4). Since p53 Arg variant is considered as wild type therefore we took Arg/Arg as a reference for analysis. We also The individuals carriers of Arg/Pro and Pro/--- versus Arg/Arg (wild type)had 1.72 (95\% CI: 1.088-2.719) and 1.659 (95\% CI: 1.068-2.578) fold higher risk of developing colon cancer, respectively. The possible reason that Pro/Pro did not show association with the risk of CRC because of small sample size. Our results confirm the earlier observation that Pro/--- is associated with colon cancer in Swedish population [10]. Some studies results are also in agreement with our findings [32-35] while some other did not find such differences between healthy controls and patient groups [14,36-39]. The discrepancies in the results can be attributed to; different ethnic population, life style, feeding habits, different latitude and various techniques used to determine genotypes of individuals participating in the studies.

With regard to MDM2 SNPT309G we did not observe any association between MDM2 (TT versus TG, GG and GG+TG presented OR of $0.93,0.709$ and 0.88 respectively) and colon carcinoma. Our findings are supported by the observations made by earlier studies [22,24,37], which proposes that MDM2 SNPT309G polymorphism alone does not associate with colon carcinoma. However, our results are contrary to some recent study reports where compared with TT, GG polymorphic variant was reported to associate with the risk of developing CRC $[14,25,40]$. The possible reason of discrepancy is due to different ethnic background of the patients in various studies.

We also compared polymorphic variants with different clinical and pathological parameters to see if polymorphisms have any association with tumor progression. None of the parameters showed significant association with either polymorphism. However, when we dichotomized p53 and MDM2 polymorphisms (p53; Arg/Arg and Pro/--, MDM2; TT and TG/GG), TT showed significant association with low-differentiated tumors (Table 4). TT variant also showed an increasing trend of left sided colon carcinoma, lymph node metastasis, distant metastasis and higher Duke stages of colon carcinoma ( $\mathrm{P}$ value; $0.089,0.094,0.07$ and 0.094 , respectively). Similar results were also observed by another study conducted previously, where p53 R72P was found to associate non-significantly with all clinicopathological parameters except with tumor size [35]. However, our results are contrary to the observation of Mammano et al. [11], who showed that proline allele is associated with tumor wall penetration, tumor grading and distant metastasis. The possible reason for this discrepancy may be due to different populations studied.

With respect to MDM2 polymorphism, association of TT with lower grade tumors, and increasing trend with advance staged tumors suggests that in colon carcinoma its expression may be affected by the status of TP53. Most of the earlier studies did not correlate MDM2 SNP 309 with different clinicopathological parameters except for the gender and age of the onset of disease [41,42]. One recent study, however, reported no association between MDM2 and tumor differentiation [40]. Some studies correlated GG with early onset of disease while other reported insignificant results [37,41,42]. Therefore, further studies in different ethnic population with relatively large population size are required to solve such discrepancies.

In survival analyses, we found that individuals with Arg/Pro and Pro/--- have a 1.75 and 1.7 fold increased risk of dying earlier with a median age of 30 (95\% CI: 12.0-48.0) and 29 months (95\% CI: 14.1-43.8) of overall survival respectively, when compared with an average of 43 months of survival for the entire patient population (we could not get median age of survival for Arg/Arg, because more than $50 \%$ people in this group were alive). Similar results are also presented in previous study [12].

For MDM2 polymorphisms, we did not observe association with overall patient survival, when TT was taken as a reference (Figure 3 and Table 5). Compared TG/GG versus TT, unadjusted values showed 
Page 7 of 8

worse overall survival for patients with TT (data not shown), but when adjusted for age, gender, tumor differentiation and stages such a correlation was not observed (Table 5). Our results are contrary to a recent study in which individual carriers of TT were reported to have better overall survival compared with other variants of MDMD2 [40], but consistent with previous study on lung carcinoma [43].

Different combinations of $\mathrm{p} 53$ and MDM2 polymorphic variants presented non-significant differences between control and colon cancer patients, when different polymorphic combinations were compared with the Arg/Arg+TT group (Table 4). Similar results have been reported by two earlier studies for various combination of p53 and MDM2 polymorphism [22,24]. However, when Arg/Arg+TG/GG was taken as a reference, Pro/--+TG/GG grouped variables showed marginally significant results. Whereas, Pro/--+TT combination showed increasing trend of correlation with colon carcinoma, however, the results were non-significant. Such observation suggests that status of p53 may determine the expression and or activity of MDM2 SNPT309G. However, none of the study reported a comparison between these groups. Hence, further observations in relatively larger population and in vitro studies are required to make final conclusion.

We also found non-significant results for combined survival analysis, except when we compared Pro/--+TT versus Arg/Arg +TG/GG; carriers of Pro/--- and TT had poor survival (OR; 2.33, 95\% CI; 1.029-4.017) (Figure 3). Earlier studies on colon carcinoma did not correlated combined polymorphic variants with patient survival. However, our results for overall patient survival are in agreement with the previous study on breast carcinoma, in which Boersma et al. reported that patients with Pro/-- and TT polymorphisms had worse overall survival.

The limitations of our study are unavailability of sufficient information such as age, smoking status and body mass index of healthy individuals that are potential risk factors for colon carcinomas. Furthermore, though we had 151 colon carcinoma patients and 188 healthy individuals, comparatively larger population would be required to improve further the quality of research.

In conclusion, we found that $\mathrm{p} 53 \mathrm{R} 72 \mathrm{P}$ polymorphism is associated with a higher risk developing of colon cancer, and patient survival in the Swedish population. Furthermore, MDM2 SNPT309G did not show any association with colon carcinoma and overall patient survival, but was correlated with lower tumor differentiation. Moreover, in combined analysis, Pro/---- TG/GG (Arg/Arg, TG/GG as reference) was marginally associated with colon carcinoma and Pro/--+TT was significantly correlated with overall poor patients survival. The combined polymorphic results suggest that interaction between p53 R72P and MDM2 SNPT309G appears to exist, which eventually modifies the association with colon carcinoma incidence and patients overall survival. Therefore, after further confirmatory studies, different polymorphic variants of p53 and or MDM2 can be used to determine individuals with high risk of developing CRC, and CRC patients who will have poor prognosis.

\section{Acknowledgement}

We thank Nyckelfonden, Örebro University hospital, Örebro, Sweden and Lions Cancer research foundation, Uppsala, Sweden, for grants funding this study.

\section{References}

1. Dusek L, Muzik J, Maluskova D (2014) Epidemiology of colorectal cancer: international comparison. 3rd European colorectal days: Brno 2014-screening and prevention; Brno, Czech Republic 2014.

2. Jin S, Levine AJ (2001) The p53 functional circuit. J Cell Sci 114: 4139-4140.

3. Marte B (2002) Cancer: super p53. Nature 420: 279.

4. Ventura A, Kirsch DG, McLaughlin ME, Tuveson DA, Grimm J, et al. (2007) Restoration of p53 function leads to tumour regression in vivo. Nature 445: 661-665.

5. Hollstein M, Sidransky D, Vogelstein B, Harris CC (1991) p53 mutations in human cancers. Science 253: 49-53.

6. Levine AJ, Momand J, Finlay CA (1991) The p53 tumour suppressor gene. Nature 351: 453-456.

7. Muller PA, Vousden KH (2014) Mutant p53 in cancer: new functions and therapeutic opportunities. Cancer Cell 25: 304-317.

8. Sullivan A, Syed N, Gasco M, Bergamaschi D, Trigiante G, et al. (2004) Polymorphism in wild-type p53 modulates response to chemotherapy in vitro and in vivo. Oncogene 23: 3328-3337.

9. Sakamuro D, Sabbatini P, White E, Prendergast GC (1997) The polyproline region of $\mathrm{p} 53$ is required to activate apoptosis but not growth arrest. Oncogene 15: 887-898.

10. Sjalander A, Birgander R, Athlin L, Stenling R, Rutegard J, et al. (1995) P53 germ line haplotypes associated with increased risk for colorectal cancer. Carcinogenesis 16: 1461-1464.

11. Mammano E, Belluco C, Bonafe M, Olivieri F, Mugianesi E, et al. (2009) Association of p53 polymorphisms and colorectal cancer: modulation of risk and progression. Eur J Surg Oncol 35: 415-419.

12. Katkoori VR, Jia X, Shanmugam C, Wan W, Meleth S, et al. (2009) Prognostic significance of p53 codon 72 polymorphism differs with race in colorectal adenocarcinoma. Clin Cancer Res 15: 2406-2416.

13. Tang NP, Wu YM, Wang B, Ma J (2010) Systematic review and metaanalysis of the association between P53 codon 72 polymorphism and colorectal cancer. Eur J Surg Oncol 36: 431-438.

14. Abderrahmane R, Louhibi L, Moghtit FZ, Boubekeur A, Benseddik K, et al. ( 2015) TP53 Arg 72Pro and MDM2 SNP309 polymorphisms and colorectal cancer risk: a west Algerian population study. Pathol Oncol Res 21: 629-635.

15. De Oliveira LP, López I, Dos Santos EM, Tucci P, Marín M, et al. (2014) Association of the p53 codon 72 polymorphism with clinicopathological characteristics of colorectal cancer through mRNA analysis. Oncol Rep 31: 1396-1406

16. Whibley C, Pharoah PD, Hollstein M (2009) p53 polymorphisms: cancer implications. Nat Rev Cancer 9: 95-107.

17. Barak $Y$, Juven T, Haffner R, Oren M (1993) $\mathrm{mdm} 2$ expression is induced by wild type p53 activity. EMBO J 12: 461-468.

18. Misra C, Majumder M, Bajaj S, Ghosh S, Roy B, et al. ( 2009) Polymorphisms at p53, p73, and MDM2 Loci Modulate the Risk of Tobacco Associated Leukoplakia and Oral Cancer. Mol Carcinog 48: 790-800.

19. Alhopuro P, Ylisaukko-Oja SK, Koskinen WJ, Bono P, Arola J, et al. (2005) The MDM2 promoter polymorphism SNP309T-->G and the risk of uterine leiomyosarcoma, colorectal cancer, and squamous cell carcinoma of the head and neck. J Med Genet 42: 694-698.

20. Momand J, Jung D, Wilczynski S, Niland J (1998) The MDM2 gene amplification database. Nucleic Acids Res 26: 3453-3459.

21. Oliner JD, Kinzler KW, Meltzer PS, George DL, Vogelstein B ( 1992) Amplification of a gene encoding a p53-associated protein in human sarcomas. Nature 358: 80-83.

22. Joshi AM, Budhathoki S, Ohnaka K, Mibu R, Tanaka M, et al. (2011) TP53 R72P and MDM2 SNP309 polymorphisms and colorectal cancer risk: the Fukuoka Colorectal Cancer Study. Jpn J Clin Oncol 41: 232-238.

23. Alazzouzi H, Suriano G, Guerra A, Plaja A, Espín E, et al. (2007) Tumour selection advantage of non-dominant negative P53 mutations in 
Citation: Mannan A, Ahmad A, Hahn-Strömberg V (2016) p53 R72P Alone and in Combination with MDM2 SNP T309G is Associated with Colon Carcinoma Incidence and Survival. J Carcinog Mutagen 7: 266. doi:10.4172/2157-2518.1000266

Page 8 of 8

homozygotic MDM2-SNP309 colorectal cancer cells. J Med Genet 44 75-80.

24. Zhang Y, Liu L, Tang Y, Chen C, Wang Q, et al. (2012) Polymorphisms in TP53 and MDM2 contribute to higher risk of colorectal cancer in Chinese population: a hospital-based, case-control study. Mol Biol Rep 39: 9661-9668.

25. Wang W, Du M, Gu D, Zhu L, Chu H, et al. (2014) MDM2 SNP309 polymorphism is associated with colorectal cancer risk. Sci Rep 4: 4851.

26. Själander A, Birgander R, Saha N, Beckman L, Beckman G (1996) p53 polymorphisms and haplotypes show distinct differences between major ethnic groups. Hum Hered 46: 41-48.

27. Hori Y, Miyabe K, Yoshida M, Nakazawa T, Hayashi K, et al. (2015) Impact of TP53 codon 72 and MDM2 SNP 309 polymorphisms in pancreatic ductal adenocarcinoma. PLoS One 10: e0118829.

28. Ashton KA, Proietto A, Otton G, Symonds I, McEvoy M, et al. (2009) Polymorphisms in TP53 and MDM2 combined are associated with high grade endometrial cancer. Gynecol Oncol 113: 109-114.

29. Bond GL, Hu W, Bond EE, Robins H, Lutzker SG, et al. (2004) A single nucleotide polymorphism in the MDM2 promoter attenuates the p53 tumor suppressor pathway and accelerates tumor formation in humans. Cell 119: 591-602.

30. Yang Y, Xia T, Li N, Zhang J, Cong W, et al. ( 2013) Combined effects of p53 and MDM2 polymorphisms on susceptibility and surgical prognosis in hepatitis B virus-related hepatocellular carcinoma. Protein Cell 4: 71-81.

31. Kaderi MA, Mansouri M, Zainuddin N, Cahill N, Gunnarsson R, et al. (2010) Lack of association between the MDM2 promoter polymorphism SNP309 and clinical outcome in chronic lymphocytic leukemia. Leuk Res 34: 335-339.

32. Gemignani F, Moreno V, Landi S, Moullan N, Chabrier A, et al. (2004) A TP53 polymorphism is associated with increased risk of colorectal cancer and with reduced levels of TP53 mRNA. Oncogene 23: 1954-1956.

33. Koushik A, Tranah GJ, Ma J, Stampfer MJ, Sesso HD, et al. (2006) p53 Arg72Pro polymorphism and risk of colorectal adenoma and cancer. Int J Cancer 119: 1863-1868.
34. Lima JM, Serafim PV, Silva ID, Forones NM (2006) [Role of the genetic polymorphism of p53 (codon 72) gene in colorectal cancer]. Arq Gastroenterol 43: 8-13

35. Zhu ZZ, Wang AZ, Jia HR, Jin XX, He XL, et al. (2007) Association of the TP53 codon 72 polymorphism with colorectal cancer in a Chinese population. Jpn J Clin Oncol 37: 385-390.

36. Cenci M, French D, Pisani T, Alderisio M, Lombardi AM, et al. (2003) p53 polymorphism at codon 72 is not a risk factor for cervical carcinogenesis in central Italy. Anticancer Res 23: 1385-1387.

37. Sotamaa K, Liyanarachchi S, Mecklin JP, Järvinen H, Aaltonen LA, et al. (2005) p53 codon 72 and MDM2 SNP309 polymorphisms and age of colorectal cancer onset in Lynch syndrome. Clin Cancer Res 11: 6840-6844.

38. Schneider-Stock R, Mawrin C, Motsch C, Boltze C, Peters B, et al. (2004) Retention of the arginine allele in codon 72 of the p53 gene correlates with poor apoptosis in head and neck cancer. Am J Pathol 164: 1233-1241.

39. Olschwang S, Laurent-Puig P, Vassal A, Salmon RJ, Thomas G (1991) Characterization of a frequent polymorphism in the coding sequence of the Tp53 gene in colonic cancer patients and a control population. Hum Genet 86: 369-370.

40. Chaar I, Arfaoui TA, El Amine eH, Mahmoud LB, Khiari M, et al. (2012) Impact of MDM2 polymorphism: increased risk of developing colorectal cancer and a poor prognosis in the Tunisian population. Eur J Gastroenterol Hepatol 24: 320-327.

41. Bond GL, Menin C, Bertorelle R, Alhopuro P, Aaltonen LA, et al. (2006) MDM2 SNP309 accelerates colorectal tumour formation in women. J Med Genet 43: 950-952.

42. Menin C, Scaini MC, De Salvo GL, Biscuola M, Quaggio M, et al. (2006) Association between MDM2-SNP309 and age at colorectal cancer diagnosis according to p53 mutation status. J Natl Cancer Inst 98: 285-288.

43. Liu L, Wu C, Wang Y, Zhong R, Duan S, et al. (2011) Combined effect of genetic polymorphisms in p53, P73, and MDM2 on non-small cell lung cancer survival. J Thorac Oncol 6: 1793-1800. 